\title{
MANUFACTURING OF THE CMC NOSE CAP FOR THE EXPERT SPACECRAFT
}

\author{
Christian Zuber, Thomas Reimer, Kornelia Stubicar, Bernhard Heidenreich, Hermann Hald \\ DLR - German Aerospace Center \\ Institute of Structures and Design \\ Pfaffenwaldring 38-40 \\ D-70569 Stuttgart
}

\begin{abstract}
DLR is responsible for the manufacturing of the CMC nose cap for the experimental re-entry spacecraft EXPERT. The goal of the EXPERT project led by the European Space Agency ESA is to collect aerothermodynamic data during atmospheric re-entry. The challenge was to manufacture a large (diameter: $716 \mathrm{~mm}$, height: $413.5 \mathrm{~mm}$ ) nose cap structure with integrated load introduction elements via the liquid silicon infiltration process (LSI) developed by DLR [1]. Two major requirements were the stagnation point temperature of $2000{ }^{\circ} \mathrm{C}$ and the aerodynamic pressure of 3 bar. The LSI process is divided into three main steps - the CFRP manufacturing, the pyrolysis and the siliconizing. To reduce internal stresses, which can cause delaminations on multi curved parts during pyrolysis, the CFRP layup was modified. The size of the prepreg patches was adapted, the fiber orientation was varied and the fiber length of the fabric layers was shortened with a cutting tool. To prevent distortions of the nose cap during the pyrolysis, a new $\mathrm{C} / \mathrm{C}$ framing was used. To transmit the loads caused by the stagnation point pressure from the nose cap into the substructure, 16 load introduction elements were joined by the socalled in situ joining into the nose cap. The launch of the nose cap as a part of the EXPERT spacecapsule is scheduled for 2010. In this paper the manufacturing process of the nose cap is described in detail. Furthermore results from the load introduction element tests and from the full-scale tests are presented.
\end{abstract}

\section{INTRODUCTION}

The Instrumented Nose Assembly (NAP) is a sub-system of the EXPERT vehicle [2][3][4], consisting of the CMC nose cap and embedded payloads to measure important aerothermodynamic data like temperature, heat flux and spectroscopic data. EXPERT will be launched on a sub-orbital trajectory with a peak velocity of $5 \mathrm{~km} / \mathrm{s}$ (Figure 1). The launch will be carried out from a submarine in the Pacific ocean using a converted Russian military system, the Volna rocket. The maximum altitude will be approximately $120 \mathrm{~km}$ with a total traveled downrange distance of $1600 \mathrm{~km}$, with $520 \mathrm{~km}$ after entry interface at $100 \mathrm{~km}$ altitude. The landing will take place in Eastern Russia on the peninsula of Kamchatka.

During re-entry the peak heat flux will reach up to $1.5 \mathrm{MW} / \mathrm{m}^{2}$ in the stagnation area assuming a partial catalytic behaviour of the Ceramic Matrix Composite (CMC) material of the nose cap. Since EXPERT is a ballistic vehicle with a relatively high ballistic coefficient the total pressure in the stagnation area reaches a value of up to $3 \mathrm{bar}$, the deceleration peak load factor is $15 \mathrm{~g}$. The aerothermal environment for the EXPERT vehicle during re-entry is typical for a ballistic flight from low earth orbit with a relatively small capsule. The ballistic factor is for most of the time during the peak load phase slightly below $1000 \mathrm{~kg} / \mathrm{m}^{2}$. The aerothermodynamic environment was looked at more closely in [5]. EXPERT in general accommodates fourteen experiments related to the topic of re-entry aerothermodynamics. 


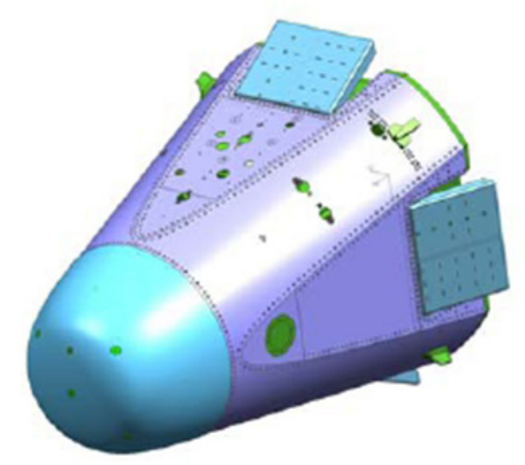

Figure 1: EXPERT vehicle

\section{LIQUID SILICON INFILTRATION (LSI) PROZESS}

The manufacturing of C/C-SiC composites by the Liquid Silicon Infiltration (LSI) process can be split into three major steps (Figure 2). Basically the process starts with the fabrication of carbon fiber reinforced plastic (CFRP) composites. It's essential to use phenolic precursor matrices of high carbon yield therefore. After curing, the composites are tempered for $4 \mathrm{~h}$ at $240{ }^{\circ} \mathrm{C}$ to complete the polymerization of the matrix as well as to initiate first matrix cracks. Subsequently, these CFRP composites are pyrolysed in a two step process. Firstly the CFRP composites are pyrolysed under inert atmosphere (e.g. nitrogen) at a temperature of $900{ }^{\circ} \mathrm{C}$ to convert the polymer matrix to amorphous carbon. Afterwards the $\mathrm{C} / \mathrm{C}$ composites are heat-treated under vacuum at a temperature of $1650^{\circ} \mathrm{C}$. The pyrolysis of the polymer matrix leads to a macroscopic shrinkage and forms a microscopic network of cracks within the resulting $\mathrm{C} / \mathrm{C}$ composites. The siliconizing is the third and final processing step. During the siliconizing the capillary effect of the translaminar crack system and the low viscosity of the molten silicon enable a quick filling of the micro cracks with molten silicon. The exothermic reaction between the carbon matrix and the molten silicon results in carbide crystals which encapsulate the carbon fibers. The siliconizing takes place under vacuum at a temperature of $1650{ }^{\circ} \mathrm{C}$. The $\mathrm{C} / \mathrm{C}$-SiC composites in principle comprise three phases. These are the carbon phase consisting of carbon fibers and residual carbon matrix, silicon carbide and a small share of unreacted silicon.

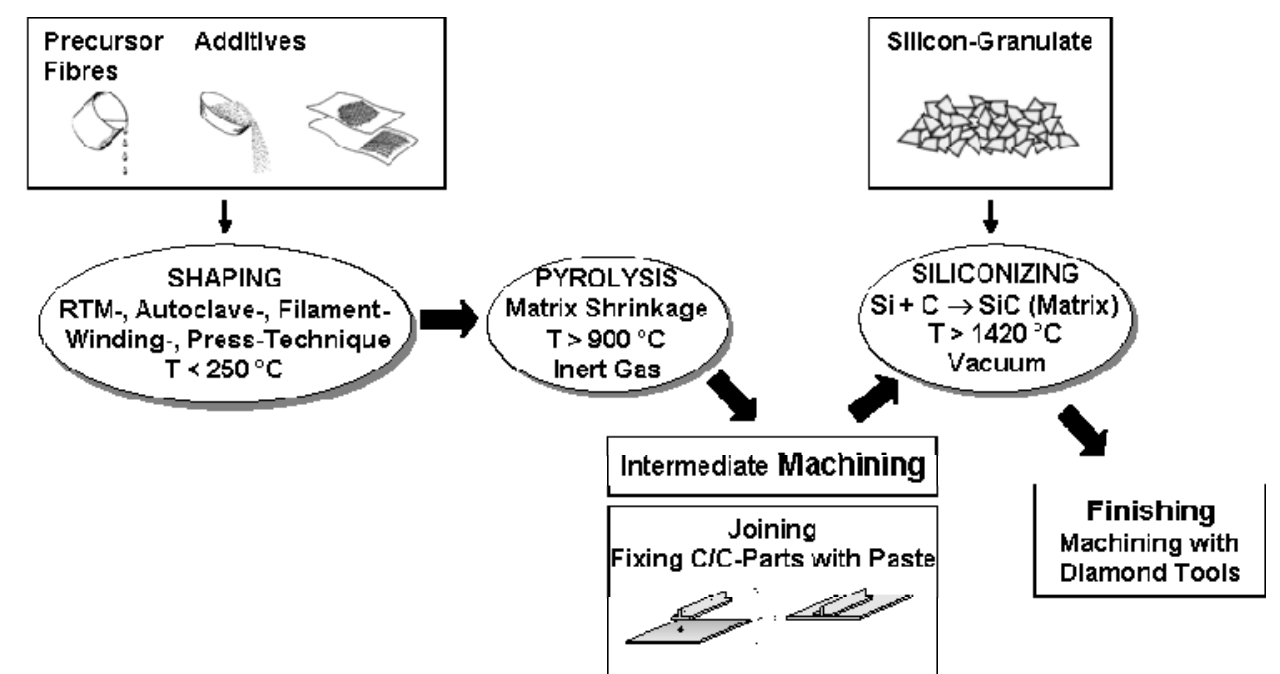

Figure 2: Liquid Silicon Infiltration (LSI) process 


\section{MANUFACTURING OF THE CFRP NOSE CAP}

In total 5 nose caps were produced during the EXPERT project. Two of them were taken through the complete LSI process and were completed as qualification and flight unit. In Table 1 an overview of all manufactured nose caps is given.

Table 1: Overview manufactured nose caps

\begin{tabular}{|l|l|l|l|}
\hline nose cap & characteristic & condition & use \\
\hline \# 1 (PH1596) & 405 pre-cut parts & $\begin{array}{l}\text { delaminations at stagnation point } \\
\text { after pyrolysis }\end{array}$ & $\begin{array}{l}\text { Siliconized (shell only), } \\
\text { pressure test }\end{array}$ \\
\hline \# 2 (PH1641) & 405 pre-cut parts & malfunction of autoclave control & $\begin{array}{l}\text { Siliconization demonstra- } \\
\text { tor with profiles }\end{array}$ \\
\hline \# 3 (PH1668) & 525 pre-cut parts & $\begin{array}{l}\text { significantly reduced delamina- } \\
\text { tions }\end{array}$ & backup \\
\hline \# 4 (PH1746) & 1428 pre-cut parts & acceptable condition & QM (qualification model) \\
\hline \# 5 (PH1800) & 1428 pre-cut parts & as \#4 & FM (flight model) \\
\hline
\end{tabular}

Based on the outer shape requirement of the final nose cap, given by ESA, an autoclave mould for the near net shape manufacture of the $\mathrm{C} / \mathrm{C}-\mathrm{SiC}$ structure was designed. During the later pyrolysis the CFRP part shrinks up to $10 \%$ in thickness direction, this shrinkage had to be taken into account when the mould was designed. The mould itself is an iron cast part which was machined on the inner surface. To allow an online monitoring of the autoclave process, the mould was equipped with 6 thermocouples. The positioning of the thermocouples is shown in Figure 3 and Figure 4.

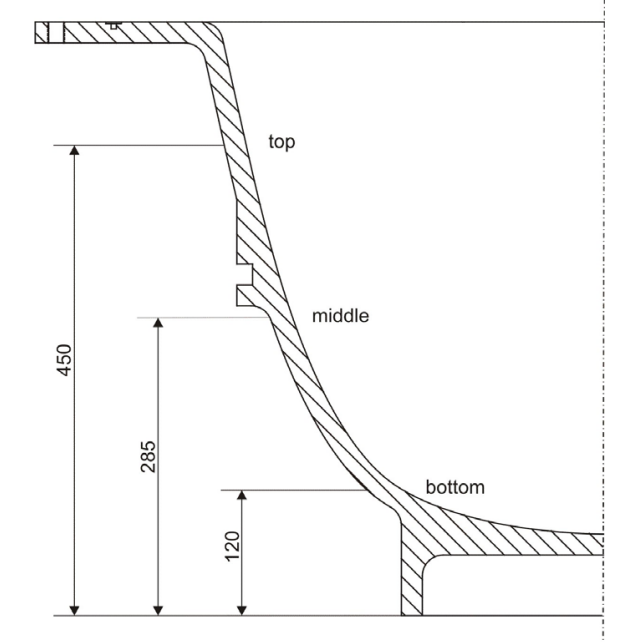

Figure 3: Position of thermocouples (vertical)

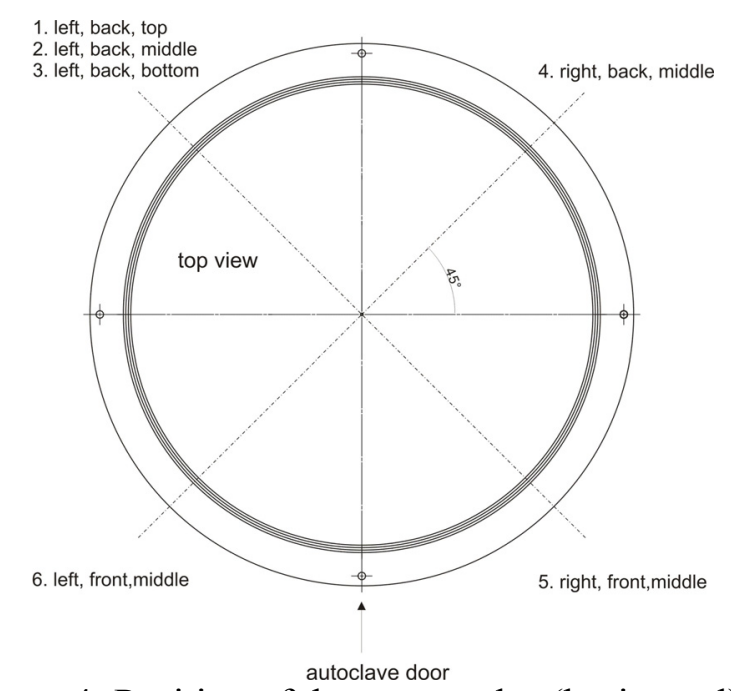

Figure 4: Position of thermocouples (horizontal)

Two laser line generators were used to allow a reproducible and accurate lay-up of the 1428 pre-cut parts for each of the nose caps \#4 and \#5. The laser line generators project two fine bright lines onto the inner surface of the mould which enclose an angle of $51.4^{\circ}$ (Figure 5). The line generators were mounted on an aluminum ring, which was fixed to the mould. On the ring they can be rotated around the rotation axis of the mould in $51.4^{\circ}$-steps. The aluminum itself can be rotated around the symmetry axis of the mold in $3.67^{\circ}$-steps. 


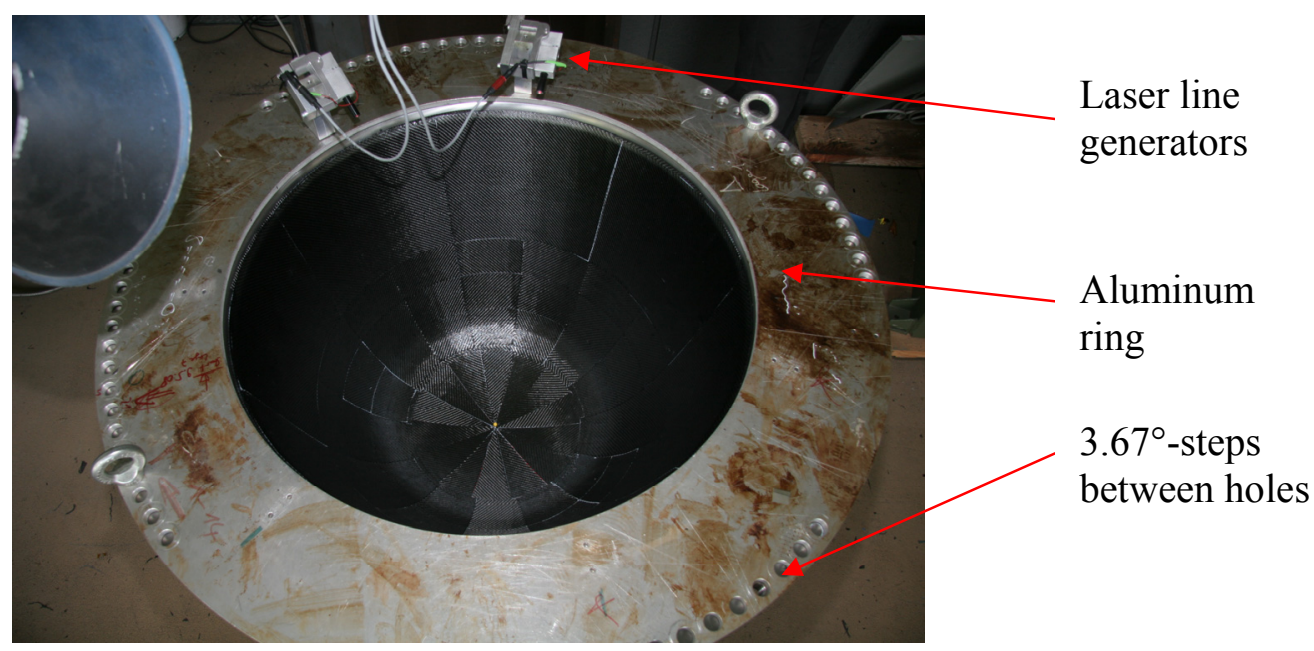

Figure 5: CFRP lay-up

\section{LAY-UP CFRP NOSE CAP}

The nose cap was built up out of 27 layers prepreg. Every layer consisted of 7 sectors, each with $51.4^{\circ}$, which again were subdivided in 7 to 9 pre cut parts. The configuration for one of these sectors is shown in Figure 6 and Figure 7. After depositing a complete prepreg layer, the aluminum ring was rotated by $3.67^{\circ}$. By this rotation a radial overlap between the edgings of the pre-cut parts was avoided.

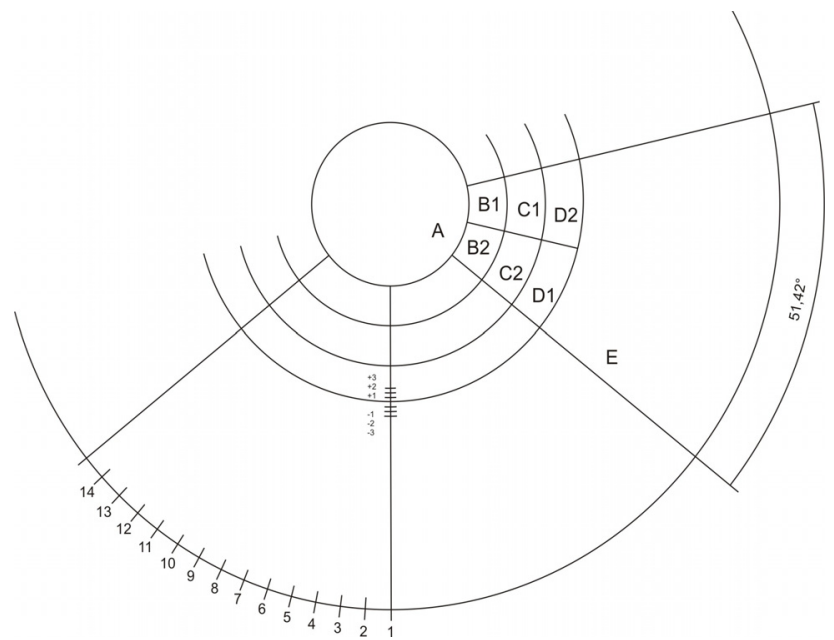

Figure 6: Pre-cut parts (layer 1-21)

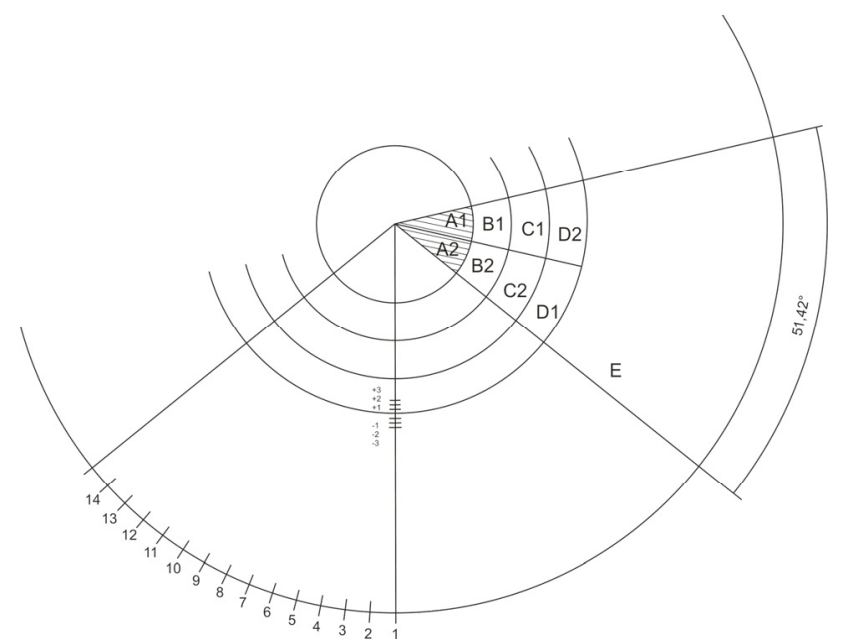

Figure 7: Pre-cut parts (layer 22-27)

For the layers 1 to 21 the pre-cut parts A, B1, B2, C1, C2, D1, D2 and E (lower half of part E) were cut with a die-cutting tool in $0^{\circ}$ and $90^{\circ}$ direction of the fabric (Figure 8). The resulting maximum fiber length was $30 \mathrm{~mm}$. The idea of cutting the fabric was to "soften" it, to avoid delaminations of the laminate during later pyrolysis. These delaminations are caused by tensions as a result of the matrix shrinkage during pyrolysis in interaction with the stiff fabric which doesn't shrink. 


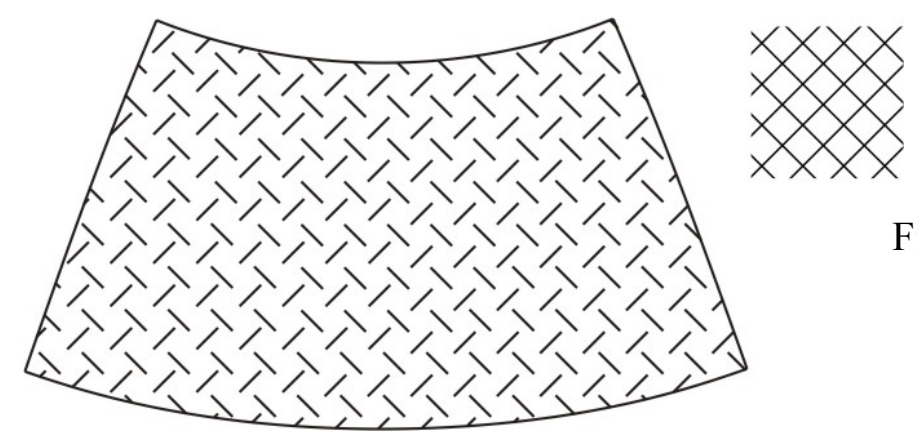

Fiber orientation $\pm 45^{\circ}$

Figure 8: Cutting pattern in $0^{\circ}$ and $90^{\circ}$ direction

For the layers 22 to 27 the fiber orientation of the pre-cut parts was changed from $\pm 45^{\circ}$ to $0^{\circ} / 90^{\circ}$. The $0^{\circ}$ direction of a single prepreg pre-cut part is shown in picture 5 (area $\mathrm{A}$ in the middle). Additionally the circular part A in the stagnation point was separated into 14 sectors. The pre-cut parts for Layer 2227 weren't cut with the die cutting tool (for details Table 2). The intention was support the delamination reduction by introducing a stiff inner structure made up of layer 22 to 27 . The shrinkage of the six inner layers in circumferential direction is due to the $0^{\circ} / 90^{\circ}$ fibre orientation extremely limited. In contrast, the outer layers can easily shrink onto the inner layers during pyrolysis, reducing inner stresses during pyrolysis.

The last prepreg layer, number 27, was covered with a release film. The release film was covered with two layers of breather material. They were necessary to suck the air out of the prepreg lay up. In addition the breather material absorbed the surplus of the phenolic precursor. To enable sufficient air suction, four glass fabric bands were placed between the nose cape center and the border of the mold. Finally the vacuum bag was placed on the set-up. After finishing the autoclave cycle $\left(\mathrm{t}=480 \mathrm{~min}, \mathrm{~T}_{\max }=\right.$ $195^{\circ} \mathrm{C}$ ), the nose cap was tempered for $4 \mathrm{~h}$ at $240{ }^{\circ} \mathrm{C}$ to complete the polymerization of the polymer matrix.

Table 2: Cut of pre-cut parts for NC4 (1428 pre-cut parts)

\begin{tabular}{|l|c|c|}
\hline Outer layers (1-21) & Fiber orientation & Cutting (in $0^{\circ}$ and $90^{\circ}$ direction of the fabric) \\
\hline A (circular) & - & yes \\
\hline B1, B2 & $\pm 45^{\circ}$ & yes \\
\hline C1, C2 & $\pm 45^{\circ}$ & yes \\
\hline D1, D2 & $\pm 45^{\circ}$ & yes \\
\hline E & $\pm 45^{\circ}$ & yes (lower half of the pre-cut part) \\
\hline Inner layers (22-27) & & no \\
\hline A1, A2 & $0^{\circ} / 90^{\circ}$ & no \\
\hline B1, B2 & $0^{\circ} / 90^{\circ}$ & no \\
\hline C1, C2 & $0^{\circ} / 90^{\circ}$ & no \\
\hline D1, D2 & $0^{\circ} / 90^{\circ}$ & no \\
\hline E1 & $0^{\circ} / 90^{\circ}$ & \\
\hline
\end{tabular}

\section{PYROLYSIS OF THE CFRP NOSE CAP}

To convert the CFRP into a porous $\mathrm{C} / \mathrm{C}$ structure, the CFRP green body was pyrolysed in a two step pyrolysis process. 


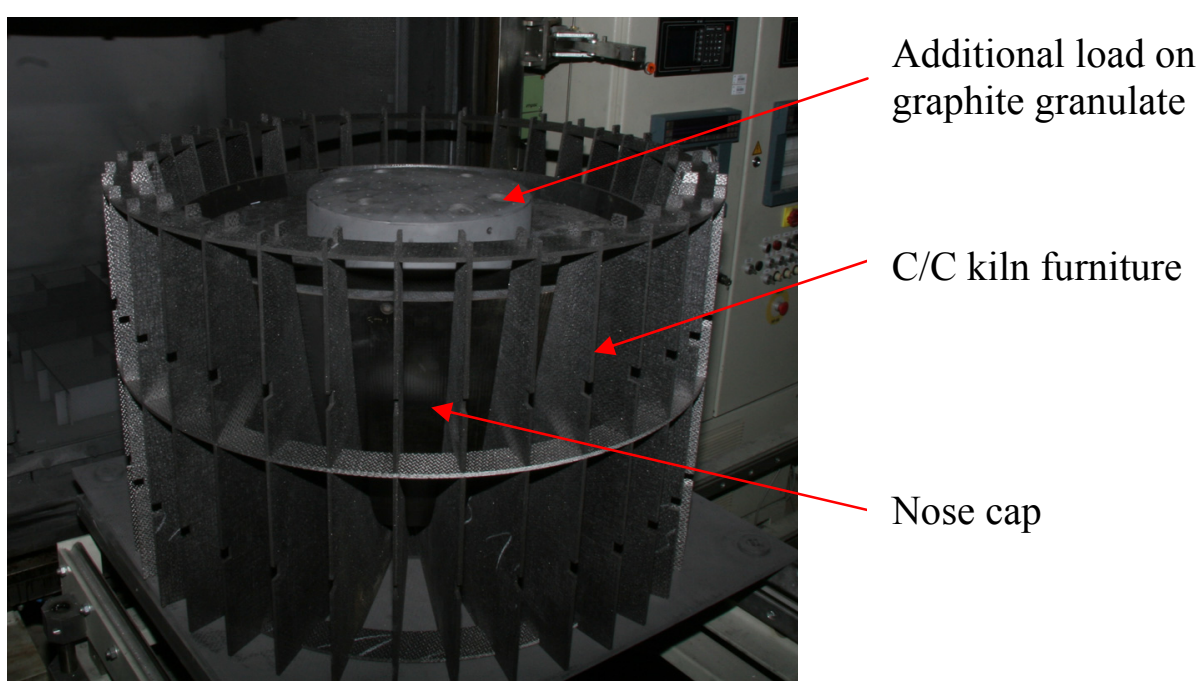

Figure 9: $\mathrm{C} / \mathrm{C}$ kiln furniture

To avoid distortion and additional inner stresses during pyrolysis, commonly massive graphite moulds are used as kiln furniture. However, a massive graphite mould couldn't be used in this case for two reasons - firstly the weight, which would exceed the maximum load of the available furnace and secondly the high procurement price. Therefore a kind of $\mathrm{C} / \mathrm{C}$ jig made out of plate material was used for the first time (Figure 9). The ribs of the jig define the reference shape for the final nose cap. To press the CFRP nose cap against the ribs, the cap was filled up with graphite granulate.

\section{MANUFACTURING OF LOAD INTRODUCTION ELEMENTS}

Each nose cap is equipped with 16 hat profiles as load introduction elements on the inside. The CFRP green bodies were made via warm pressing technique. The warm pressing technique allowed a quick and simple manufacturing of the raw profiles. Therefore 23 rectangular prepreg layers were stacked onto the positive aluminum mould. After closing the mould and forming the profile the precursor was cured during the $290 \mathrm{~min}$ lasting process $\left(\mathrm{T}_{\max }=210^{\circ} \mathrm{C}, \mathrm{p}=8 \mathrm{bar}\right)$. Figure 10 shows the female mould with the CFRP profile after polymerization as well as some surplus of the phenolic precursor, as it typically flows out of the mould during the warm pressing cycle. After finishing the subsequent tempering cycle with a maximum temperature of $250{ }^{\circ} \mathrm{C}$, the profiles were pyrolysed with the same two step pyrolysis processes used for the nose cap. Therefor the CFRP green bodies were placed in a graphite mould (Figure 11). The shape of the graphite mould corresponds to the finale shape of the hat profiles. As shown in Figure 11 the graphite mould doesn't fit to the profile in the initial CFRP condition. During pyrolysis shrinkage in thickness direction and a change of the angles of the CFRP green body occurs, which is supported by the graphite mold. After pyrolysis the mould fits exactly to the $\mathrm{C} / \mathrm{C}$ part. In the $\mathrm{C} / \mathrm{C}$ condition two hat profiles, as shown in Figure 12, were machined out of one $\mathrm{C} / \mathrm{C}$ raw profile. In the run-up to the hardware manufacturing, stress peaks in the joining area between the hat profiles and the nose cap were detected via FEM analysis. To reduce these stress peaks, intermediate elements (referred to as $\mathrm{C} / \mathrm{C}$ shoes) were joined to the hat profiles via in-situ joining (picture 10). 


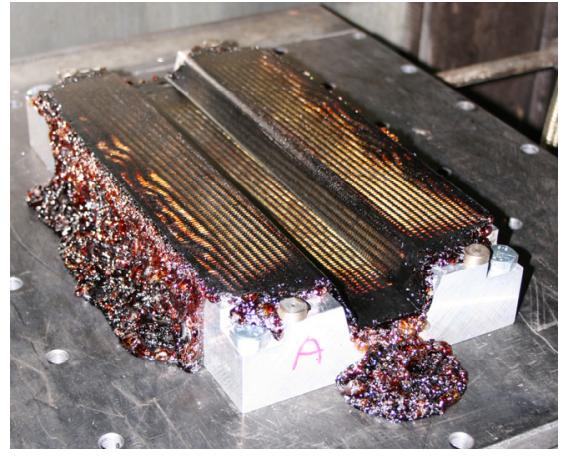

Figure 10: CFRP hat profile after polymerization

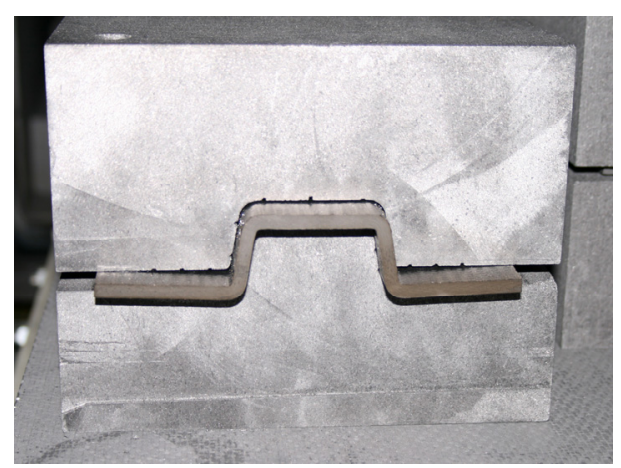

Figure 11: CFRP hat profile inside graphite kiln furniture

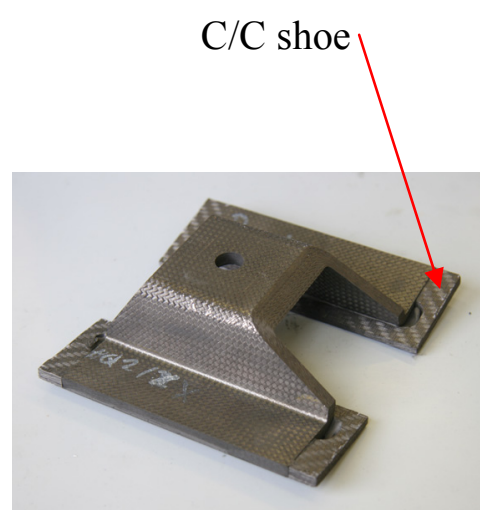

Figure 12: $\mathrm{C} / \mathrm{C}$ hat profile prepared for joining

\section{IN-SITU JOINIG OF NOSE CAP AND LOAD INTRODUCTION ELEMENTS}

After pyrolysis the nose cape was calibrated with a 3-D measuring machine. The deformations caused by the pyrolysis were rated to be in an acceptable range. Based on the $3 \mathrm{D}$ measuring results planar faces were machined as pockets into the inside of the nose cap. The hat profiles were joined into the pockets with a joining paste, developed for the LSI process. The paste is based on a phenolic resin with a high residual carbon content of approx. 60 mass- $\%$ as well as a high amount of carbon powder. The high carbon content is needed to ensure a stable joint during the subsequent Siliconization, were the polymer content of the joining past firstly is converted into carbon and subsequently transformed to $\mathrm{SiC}$.

To assure a homogeneous pressure in the entire joining area between the hat profiles and the nose cap, aluminum pushers were used, which fit to the contour of the nose cap respectively the shape of the hat profiles. The needed force during the curing of the joining paste was achieved by using heavy screw clamps which allow an operation by torque wrench. The torque wrench guarantees a reproducible joining force for all hat profiles during the curing. The joining past was cured in a tempering furnace at $\mathrm{T}_{\max .}=135^{\circ}$ for 2 hours (Figure 13).

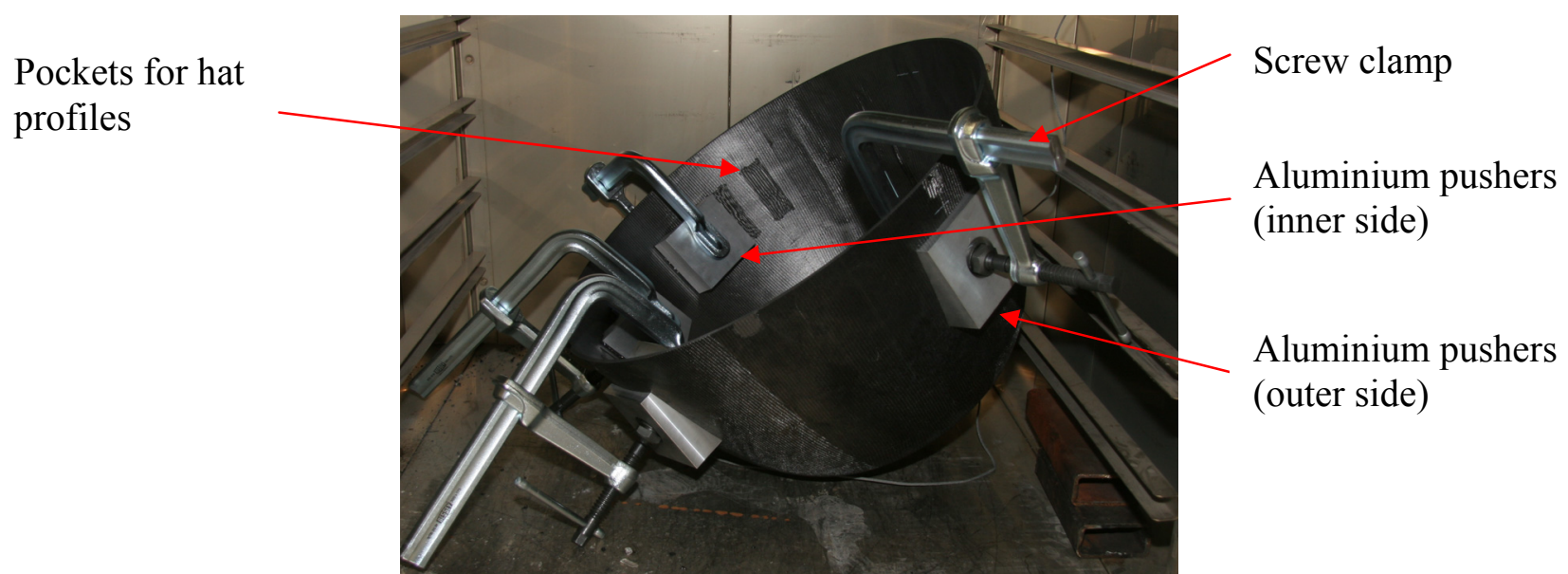

Figure 13: Curing after joining

\section{SILICONIZING OF THE NOSE CAP}

After the joining of the nose cap and the hat profiles, the nose cap was siliconized at a temperature of $1650^{\circ} \mathrm{C}$ in vacuum. Usually the offered silicon amount is calculated using the open porosity of 
the $\mathrm{C} / \mathrm{C}$ preform measured via the Archimedes principle. Because of the large dimensions of the part, a porosity measurement wasn't possible. Therefore a silicon amount of 57 mass- $\%$ of the $\mathrm{C} / \mathrm{C}$ preform was offered, as it is common for the siliconization of $\mathrm{C} / \mathrm{C}$ plates manufactured by autoclave technique. The silicon granulate was applied from the bottom (2/3 of total amount) and the top (1/3 of total amount) of the nose cap. Silicon carbide buffer plates were used to regulate the silicon infiltration during siliconizing. The whole build-up was placed in a graphite crucible which was also coated with boron nitride (Figure 14). The boron nitride coating was applied to prevent the graphite from reacting with the liquid silicon during infiltration.

After siliconizing the nose cap was inspected via computer tomography (CT) to detect inhomogeneously siliconized areas, e.g. areas which were not infiltrated with silicon as a result of delaminations. The hat profiles were considered to be particularly critical, because the silicon needed for a proper infiltration of the hat profile has to flow through the joining layer between them and the nose cap. It could be shown via CT that the silconization of the nose cap in general and the hat profiles in particular was successful - no inhomogeneously siliconized areas could be detected.

After the CT inspection the nose cap was desiliconized to remove residual free silicon which hasn't reacted to silicon carbide. The desiliconizing was done at $1650{ }^{\circ} \mathrm{C}$ in vacuum. Therefore the $\mathrm{C} / \mathrm{C}-\mathrm{SiC}$ part was partly embedded into graphite granulate which reacts with the residual silicon to silicon carbide.

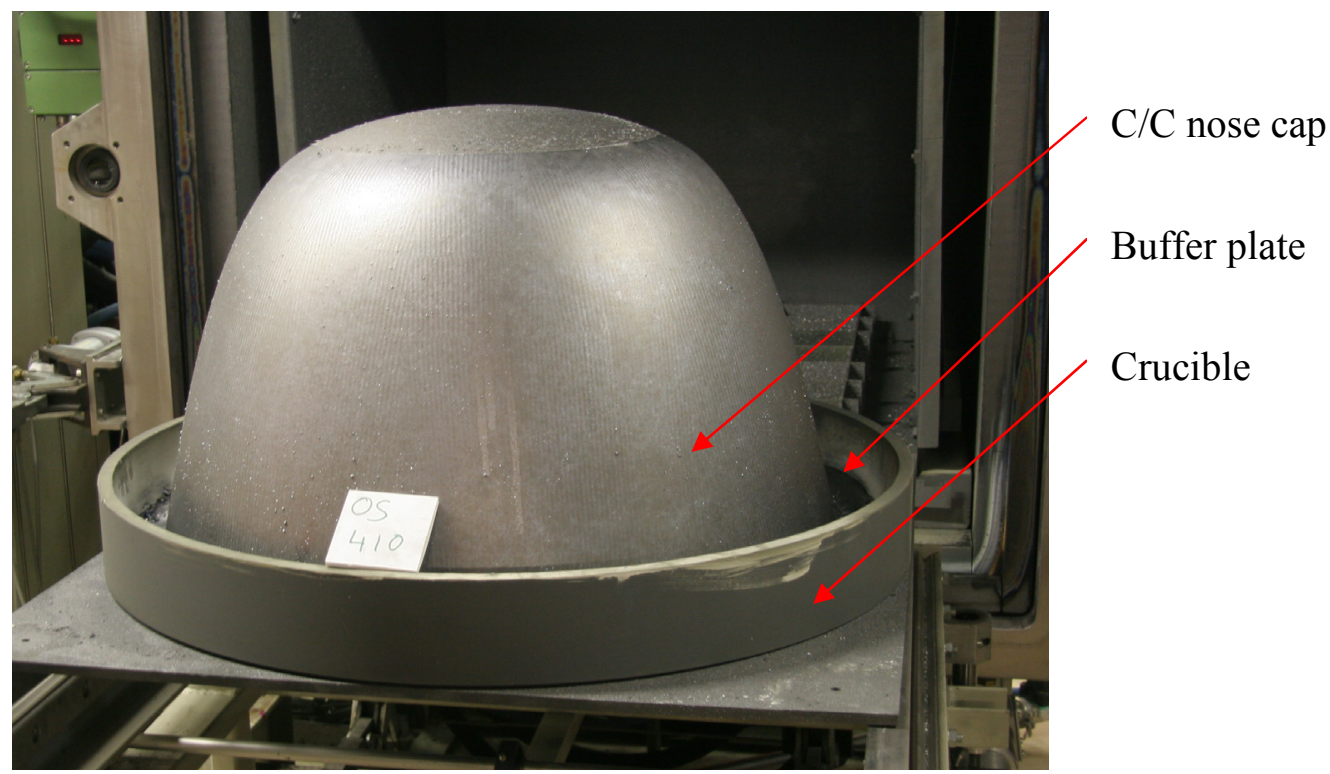

Figure 14: Siliconiziing of nose cap \#5

\section{FINAL MACHING AND COATING}

The final manufacturing steps towards a flight-ready component comprised mainly the machining of the siliconized nose cap and a coating process. In detail the following tasks had to be carried out:

- Drilling of the holes for sensor heads

- Machining of planar faces on the inside for sensor heads

- Drilling of holes in the hat profiles

- Drilling of holes on the inside for thermocouple placement

- Cutting of the nose cap to the required height

- Reduction of surface roughness (residua of siliconizing) with diamond coated abrasive pads 
- Cleaning of with osmosis water with subsequent drying at $110^{\circ} \mathrm{C}$ in tempering furnace

- CVD-SiC coating with a resulting coating thickness of $90-120 \mu \mathrm{m}$

The finished nose cap is shown in Figure 15 and Figure 16.

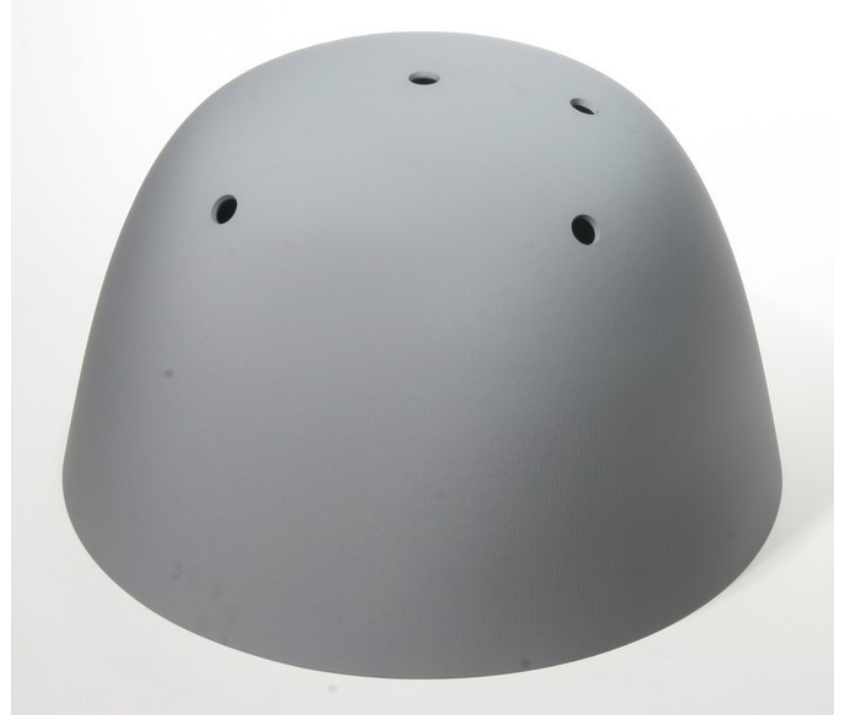

Figure 15: Finished nose cap outside view

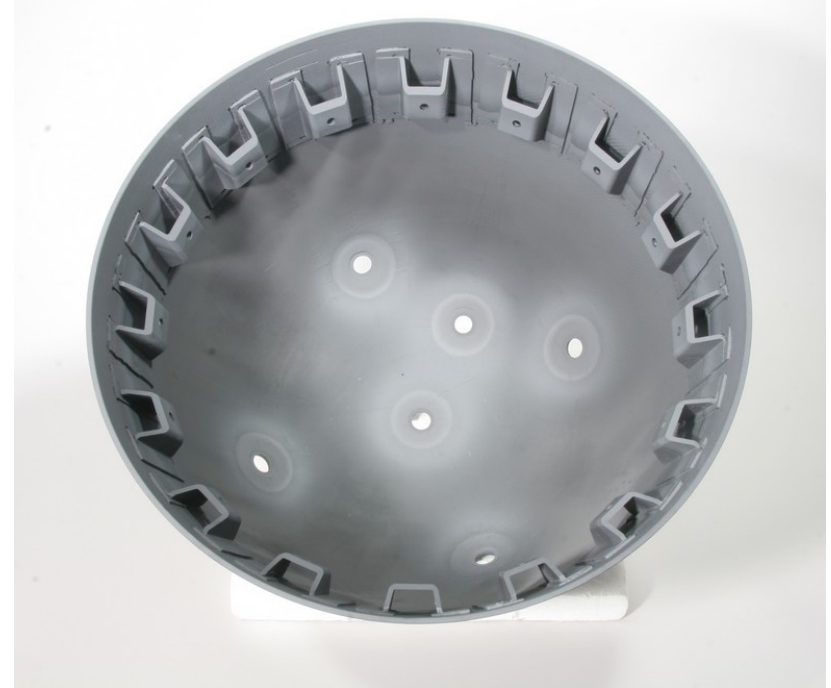

Figure 16: Finished nose cap inside view

\section{DESIGN VERIFICATION}

The design of the nose cap was verified via several major elements:

- Finite element analysis

- Pressure test of the nose shell

- Mechanical test of the load introduction elements

- Material characterization in arc jet tests

- Payload subsystem arc jet tests

Of these, the numerical analysis is not described in this paper because the focus is on the hardware and the related hardware tests. A description of some aspects of the numerical design work can be found in [6]. Also not described are the dedicated arc jet tests with material samples and the embedded elements of the sensor subsystems in the nose cap. More details on these topics can be found in [7].

\section{PRESSURE TEST OF THE NOSE CAP}

The dynamic pressure acting on the stagnation region of the nose cap is $150 \mathrm{kPa}$. This equals a total pressure of roughly $270 \mathrm{kPa}$. A pressure test with the nose shell only was carried out in order to verify that kind of load. The test was set up as a pressure difference test in the autoclave of the Institute. The nose cap was positioned on an aluminium plate as shown in Figure 17. The edge of the nose cap was sealed against the plate. Thereby a sealed volume was created enclosed by the nose cap and the plate. A vacuum line was connected to the plate and to a vacuum pump on the far end outside of the 
autoclave. The nose cap on the plate was placed in the autoclave and the pressure inside of the nose cap was decreased via the vacuum pump. At the same time the pressure in the autoclave was raised so that a pressure difference was created between the outside and inside of the nose cap. The targeted pressure difference was $300 \mathrm{kPa}$. Figure 18 shows that a maximum of $315 \mathrm{kPa}$ pressure difference was achieved. The nose cap was equipped with strain gauges during the test. The maximum recorded levels were $22 \mathrm{MPa}$ compression stress. The bending strength of the material is in the range of $180 \mathrm{MPa}$, tension strength is $120 \mathrm{MPa}$ and compression strength is $-200 \mathrm{MPa}$.

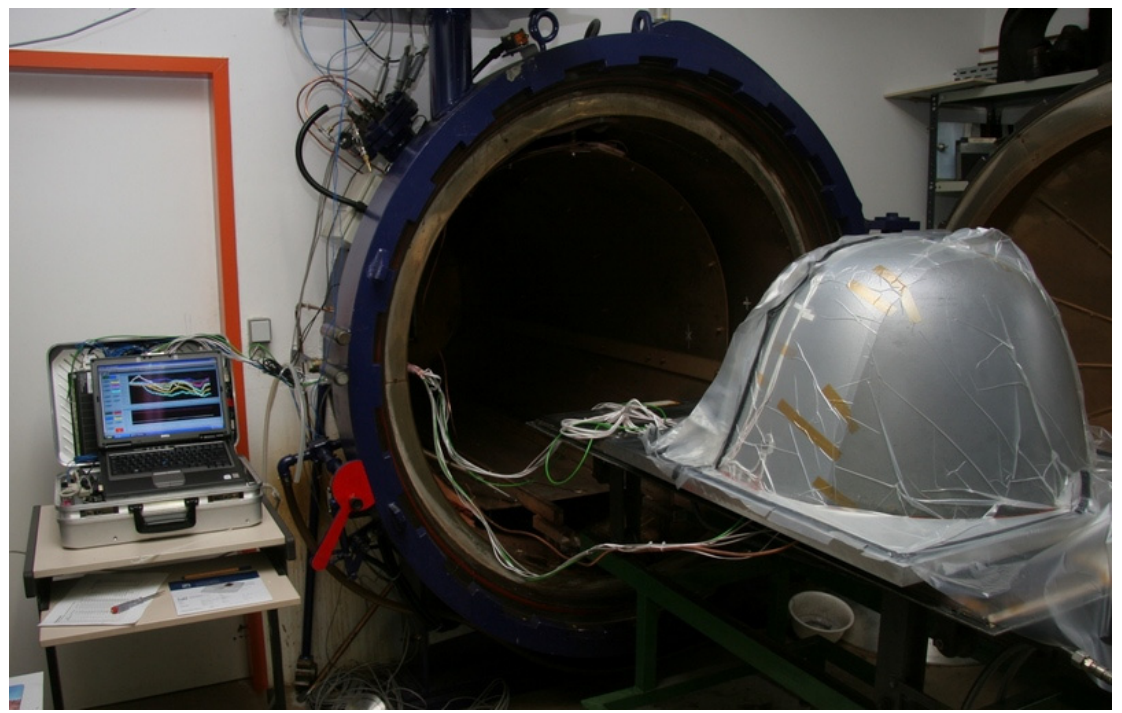

Figure 17: Nose cap pressure test

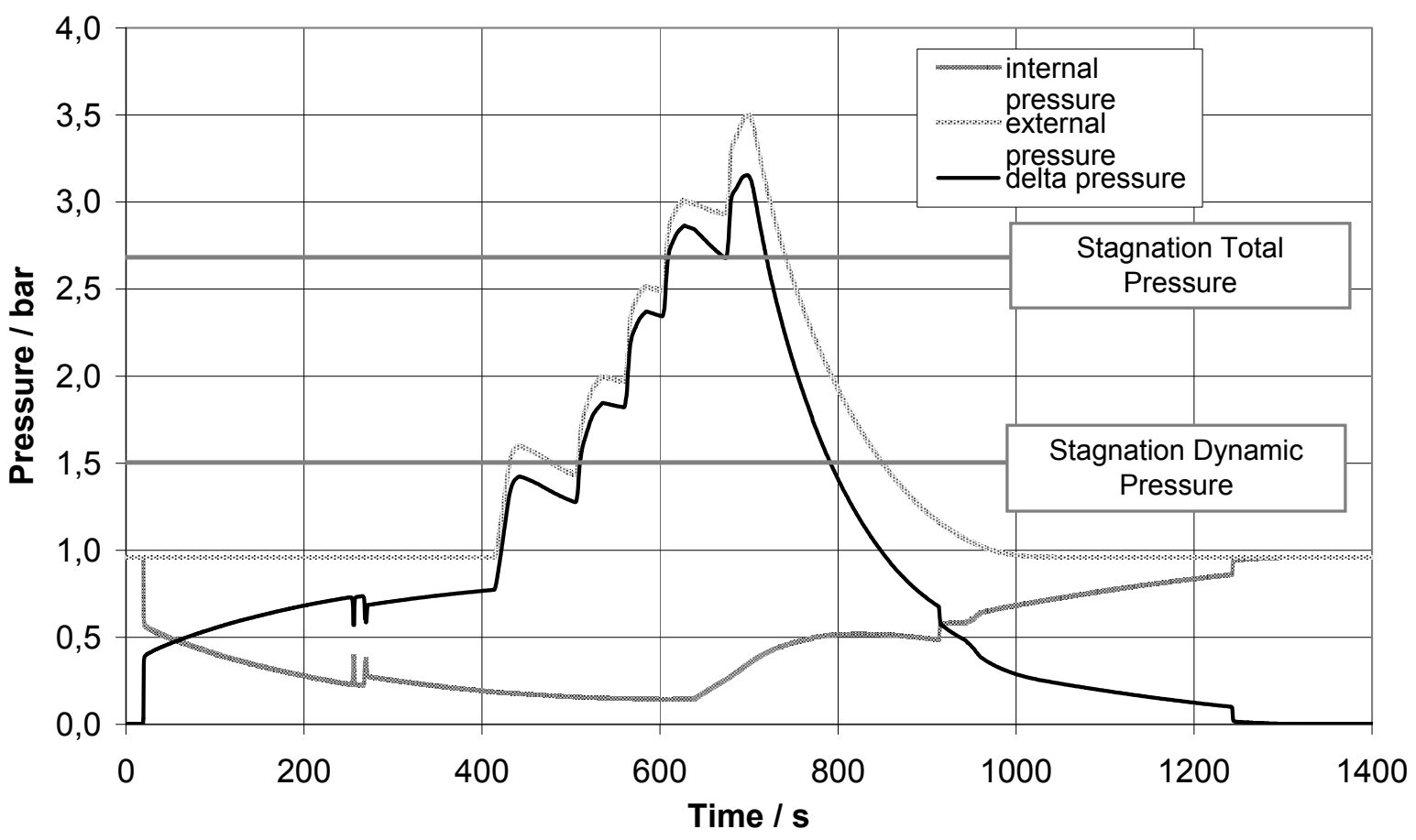

Figure 18: Nose cap pressure test recorded data

\section{LOAD INTRODUCTION ELEMENTS}


The load introduction elements on the inside of the nose cap have to transmit the aerodynamic loads from the nose cap to the structure of the capsule. An analysis of the transient deceleration loads on the vehicle resulted in a value of approximately $60 \mathrm{kN}$ that act as a mechanical load on the nose cap and have to be sustained by the load introductions. For each individual load introduction chain, that results in $3.75 \mathrm{kN}$. Since that load is due to the aerodynamic pressure it is a compression load that acts on the load transfer elements. A test was devised to verify the capability of the nose cap to handle that situation. The test was set up as a uni-axial compression test of structural samples that represent a nose cap cut-out with the corresponding hat profiles and other related components.

Figure 19 shows a sample as prepared for the testing and Figure 20 shows the test machine with a sample fixed to the lower sample holder. A number of 32 tests were carried out in total. The test parameters included mainly variations in the lay-up of the CMC components and in the materials used as shown in Table 3.

Table 3: Load introduction test parameters

\begin{tabular}{|c|c|c|c|c|c|}
\hline Test Series & Samples & Material & $\begin{array}{l}\text { Fiber orientation } \\
\text { hat profile }\end{array}$ & $\begin{array}{l}\text { Fiber orientation } \\
\text { plate }\end{array}$ & Reinforcement \\
\hline $\mathrm{a}$ & 6 & $\mathrm{XB}$ & $0^{\circ} / 90^{\circ}$ & $45^{\circ}$ & yes \\
\hline $\mathrm{b}$ & 6 & $\mathrm{XB}$ & $45^{\circ}$ & $45^{\circ}$ & no \\
\hline $\mathrm{c}$ & 6 & $\mathrm{XB}$ & $45^{\circ}$ & $45^{\circ}$ & yes \\
\hline $\mathrm{d}$ & 6 & $\mathrm{XB}-\mathrm{T} 800$ & $45^{\circ}$ & $45^{\circ}$ & yes \\
\hline $\mathrm{e}$ & 6 & $\mathrm{XB}$ & $0^{\circ} / 90^{\circ}$ & $0^{\circ} / 90^{\circ}$ & yes \\
\hline $\mathrm{f}$ & 2 & $\mathrm{XB}$ & $45^{\circ}$ & $0^{\circ} / 90^{\circ}$ & yes \\
\hline
\end{tabular}

The results of the tests were very favorable. A summary of all tests is presented in Figure 21 . The average failure load of the samples was $12.3 \mathrm{kN}$. Two failure modes could be observed. Either there was a debonding between carrier plate and profile or there was a cracking failure in the top face of the profile. Both failure types were fairly well distributed among all the tested samples.

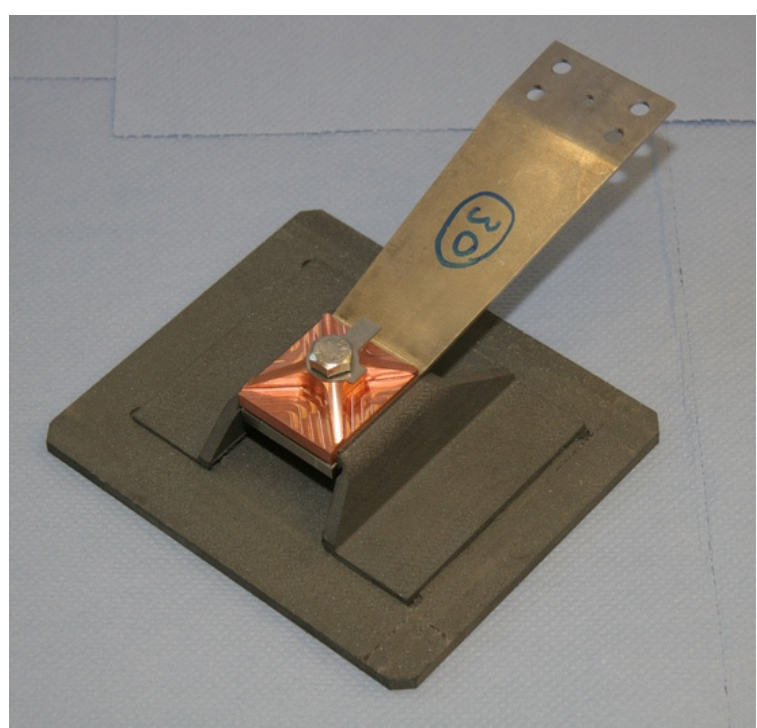

Figure 19: Load introduction test sample

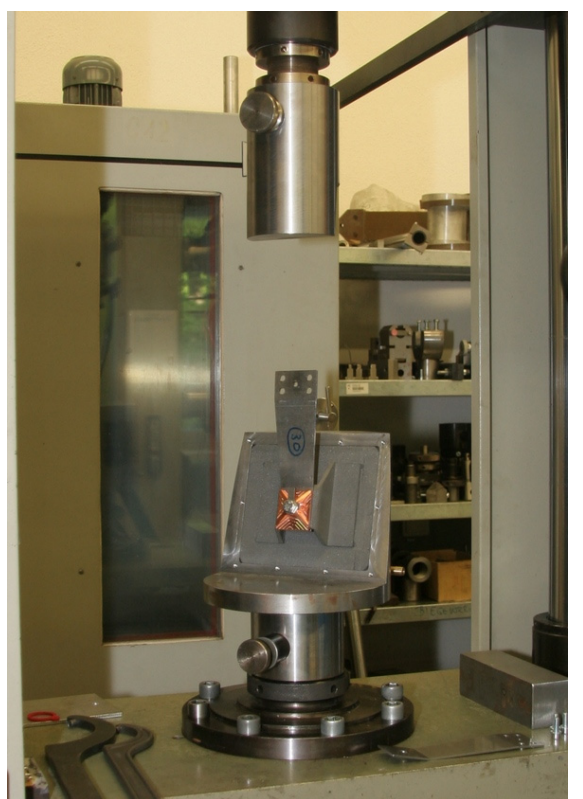

Figure 20: Load introduction test set-up 


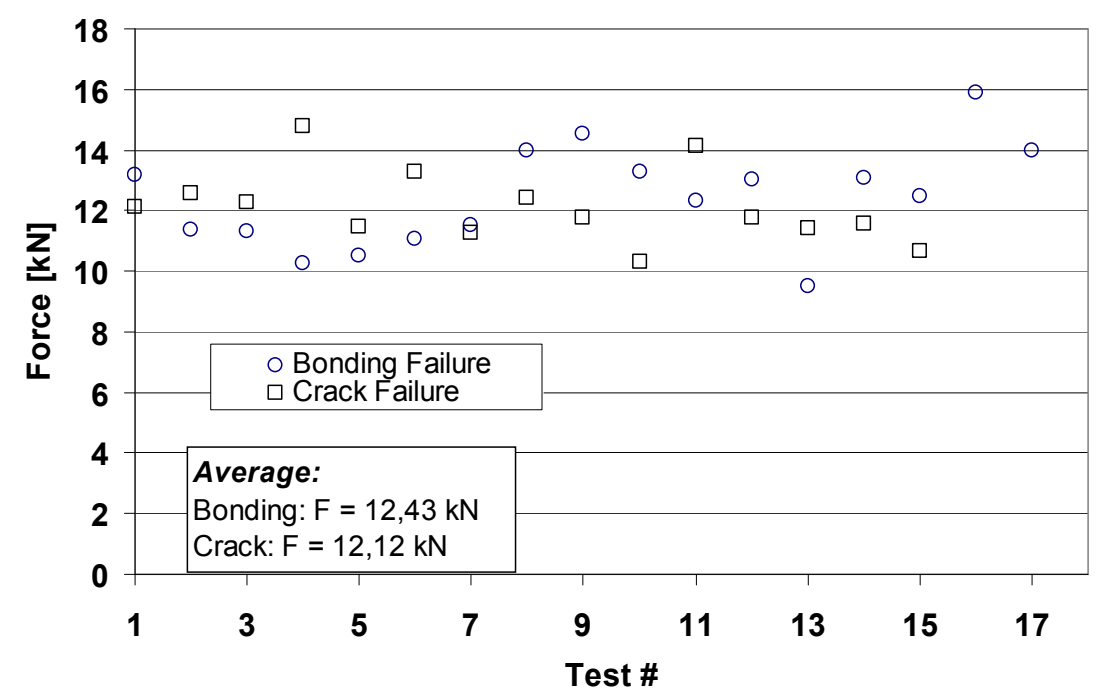

Figure 21: Load introduction test results

\section{CONCLUSIONS}

With the EXPERT nose cap, a large and complex CMC structure was successfully developed. Initial lay-up problems could be solved by the variation of the lay-up. The nose cape was siliconized successfully. It could be shown that a siliconization over the joining boundaries between the load introduction elements and nose cap is possible. During the whole manufacturing process advanced NDE equipment as e.g. computer tomography was utilized.

It becomes obvious that a further understanding of the mechanisms leading to the delaminations is required for future projects. In this context a comprehensive characterization of the remedial effects resulting from the lay-up variations should be done.

\section{REFERENCES}

[1] W. Krenkel, "Entwicklung eines kostengünstigen Verfahrens zur Herstellung von Bauteilen aus keramischen Verbundwerkstoffen", Dissertation Universität Stuttgart, DLR-Forschungsbericht 2000-04, Stuttgart, Germany, 2000

[2] F. Massobrio, R. Viotto, M. Serpico, A. Sansone, M. Caporicci, J.-M. Muylaert, „EXPERT:An atmospheric re-entry test-bed“, Acta Astronautica, Volume 60, Issue 12, June 2007, p974-985

[3] G. Reibaldi, J. Gavira, F. Ratti, S. de Mey, J-M. Muylaert, R. Provera, F. Massobrio, "EXPERT: The ESA experimental re-entry test-bed programme", $59^{\text {th }}$ International Astronautical Congress, 29 Sep.-03. Oct. 2008, Glasgow, Scotland, IAC-08.D2.6.3

[4] J. Gavira, "EXPERT - A European Aerothermodynamics In-Flight Testbed", $6{ }^{\text {th }}$ European Workshop on Thermal Protection Systems and Hot Structures, 1-3 April 2009, Stuttgart, Germany

[5] T. Reimer, T. Laux, "Thermal and Mechanical Design of the EXPERT C/C-SiC Nose", $5^{\text {th }}$ European Workshop on Thermal Protection Systems and Hot Structures, Noordwijk, The Netherlands, 17-19 May 2006 (ESA SP-631, August 2006)

[6] K. Stubicar, T. Reimer, "Thermo-Mechanical Design of the EXPERT Nose and Testing of the Load Introductions", $6^{\text {th }}$ European Workshop on Thermal Protection Systems and Hot Structures, 1-3 April 2009, Stuttgart, Germany 
[7] K. Stubicar, T. Reimer, G. Koppenwallner et al., Testing of EXPERT Nose Material and Sensor Heads in the DLR ARCJET Facilities, $6^{\text {th }}$ Symposium on Aerothermodynamics for Space Vehicles, Versailles, France, 3-6 November 2008 